\title{
(2) OPEN ACCESS \\ 'New Medicine Service': supporting adherence in people starting a new medication for a long-term condition: 26-week follow-up of a pragmatic randomised controlled trial
}

- Additional material is published online only. To view please visit the journal online (http://dx.doi.org/10.1136/ bmjqs-2018-009177).

For numbered affiliations see end of article.

\section{Correspondence to}

Professor Rachel Ann Elliott, Manchester Centre for Health Economics, School of Health Sciences, University of Manchester, Manchester M13 9PL, UK;

rachel.a.elliott@manchester. ac.uk

Received 4 December 2018 Revised 30 August 2019 Accepted 12 September 2019 Published Online First 15 November 2019

\section{Linked}

- http://dx.doi.org/10.1136/ bmjqs-2019-009984

\section{Check for updates}

(C) Author(s) (or their employer(s)) 2020. Re-use permitted under CC BY. Published by BMJ.

To cite: Elliott RA, Boyd MJ, Tanajewski L, et al.

BMJ Qual Saf

2020:29:286-295.

\section{ABSTRACT}

Objective To examine the effectiveness and costeffectiveness of the community pharmacy New Medicine Service (NMS) at 26 weeks.

Methods Pragmatic patient-level parallel randomised controlled trial in 46 English community pharmacies. 504 participants aged $\geq 14$, identified in the pharmacy when presenting a prescription for a new medicine for predefined long-term conditions, randomised to receive NMS ( $n=251)$ or normal practice $(n=253)$ (NMS intervention: 2 consultations 1 and 2 weeks after prescription presentation). Adherence assessed through patient self-report at 26-week follow-up. Intentionto-treat analysis employed. National Health Service (NHS) costs calculated. Disease-specific Markov models estimating impact of non-adherence combined with clinical trial data to calculate costs per extra qualityadjusted life-year (QALY; NHS England perspective). Results Unadjusted analysis: of 327 patients still taking the initial medicine, $97 / 170(57.1 \%)$ and $103 / 157(65.6 \%)(p=0.113)$ patients were adherent in normal practice and NMS arms, respectively. Adjusted intention-to-treat analysis: adherence OR 1.50 (95\% Cl 0.93 to 2.44, $p=0.095$ ), in favour of NMS. There was a non-significant reduction in 26-week NHS costs for NMS:

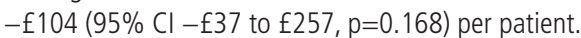
NMS generated a mean of $0.04(95 \% \mathrm{Cl}-0.01$ to 0.13$)$ more QALYs per patient, with mean reduction in lifetime cost of $-f 113.9(-1159.4,683.7)$. The incremental costeffectiveness ratio was $-\mathrm{f} 2758 / \mathrm{QALY}(2.5 \%$ and $97.5 \%$ : $-38739.5,34024.2$. NMS has an $89 \%$ probability of cost-effectiveness at a willingness to pay of $£ 20000$ per QALY.

Conclusions At 26-week follow-up, NMS was unable to demonstrate a statistically significant increase in adherence or reduction in NHS costs, which may be attributable to patient attrition from the study. Long-term economic evaluation suggested NMS may deliver better patient outcomes and reduced overall healthcare costs than normal practice, but uncertainty around this finding is high.

Trial registration number NCT01635361, ISRCTN23560818, ISRCTN23560818, UKCRN12494.

\section{INTRODUCTION}

The New Medicine Service (NMS) introduced in England in $2011^{1}$ supports people starting a newly initiated medication for a long-term condition in four specified patient groups associated with high rates of avoidable hospital admissions (asthma/chronic obstructive pulmonary disease, hypertension, type 2 diabetes, or prescription of an anticoagulant/antiplatelet agent). NMS is based on our previous work in developing and testing an intervention targeting poor medicine adherence in people receiving a new medicine for a long-term condition. $^{2-4}$ NMS is delivered by the community pharmacist supplying the medicine, either face-to-face or over the telephone. When people start a new medicine, they often experience problems which can lead to a significant proportion becoming nonadherent. ${ }^{5}$ NMS provides a starting point for the pharmacists to resolve individuals' specific problems with information and advice. Accredited pharmacies provide NMS, are remunerated for each episode of care and have guidance delivering the intervention. $^{6}$

We have already demonstrated that the NMS increases the proportion of patients 
reporting adherence to their new medicine 10 weeks after the intervention, by $10.2 \% .^{7}$ In an economic analysis modelling impact of adherence changes on health status and cost over lifetime, NMS was more effective and less costly than normal practice. ${ }^{8}$ NMS demonstrated a $96.7 \%$ probability of cost-effectiveness compared with normal practice at a willingness to pay of $£ 20000$ per quality-adjusted life-year (QALY).

As a result of this work based on effectiveness at 10-week follow-up, NMS was approved for routine commissioning in the National Health Service (NHS) in England. ${ }^{9}{ }^{10}$ New services with similar configurations, or explicitly based on NMS, have since been trialled or set up in other settings: Scotland (New Medicine Intervention Support Tools) ${ }^{11}$; Australia (New Medicines Support Service) $^{12}$; Norway (Medicines Startup-Medisinstart) ${ }^{13}$; Ireland (NMS $)^{14}$; and Belgium (Begeleidingsgesprek Nieuwe Medicatie ${ }^{15}$ and Entretien d'accompagnement de Nouvelle Médication). ${ }^{16}$

In the original trial we also measured self-reported adherence at 26-week follow-up as a secondary outcome to assess persistence of effect over time. This was in response to the lack of evidence around longer term effectiveness of interventions intended to improve adherence. If there was a reasonable degree of persistence of the effect at 26 weeks then health gains would be increased. If reasonably effective at 6 months then the approach could be incorporated into existing six monthly reviews of medication in the NHS, providing a continuous monitoring and feedback loop to improve patients' lives. In this paper, we ask the extent to which the adherence improvement and cost-effectiveness observed at 10 weeks were maintained at 26 weeks.

\section{METHODS}

\section{Study design}

The study was a patient-level multicentre, pragmatic randomised controlled trial (RCT) with parallel group design, ${ }^{17} 18$ reported according to Consolidated Standards of Reporting Trials (CONSORT) criteria. ${ }^{19}$

\section{Study setting}

Community pharmacies in East Midlands and South Yorkshire and Greater London accredited to provide NMS. Pharmacy selection took into account pharmacy ownership, proximity to general practice (GP), setting and economic deprivation. (See online supplementary appendix 1 for details.)

\section{Study participants}

Patients could participate if they were eligible for NMS, community dwelling, aged 14 or over and able to consent to the NMS and the study (parental consent for 14-15 year-olds).

\section{Pharmacy and patient recruitment}

Pharmacies from all groups covering the range of characteristics in the setting criteria above were invited to participate, those initiating at least two NMS consultations/week were recruited. Of 61 recruiting pharmacies, 46 (75.4\%) provided patients. No further training on delivering the intervention or normal practice was provided (see online supplementary appendix 1).

Patients were recruited within community pharmacies by pharmacists trained about the study. The process and outcome of being randomised was explained to patients. They were given as long as they needed to read the study information and ask questions.

\section{Randomisation and blinding}

Patients were randomised into one of the two study arms, using sealed envelopes, stratified by drug/disease group using Statistical Analysis Software (SAS V.9.3). ${ }^{20}$ Block randomisation was used within each pharmacy to avoid allocation imbalances. Researchers collecting data were blinded to study arm.

\section{NMS intervention}

NMS begins with the patient's presentation at a community pharmacy with a prescription for a new medicine. The NMS intervention comprises two parts, which can be face-to-face or over the telephone, named 'intervention' and 'follow-up'. The pharmacist invites the patient to a one-to-one consultation 7-14 days later (the 'intervention') with a 'follow-up' 14-21 days after that. These are the points in the service at which the pharmacist would ask about adherence. The NMS intervention should be completed in a maximum of 5 weeks (online supplementary appendix 2).

\section{Normal practice}

Normal practice was the pharmacist's usual advice when presented with a prescription for a new medicine for a long-term condition. No follow-up was offered to these patients.

\section{Primary (10-week adherence) and secondary outcomes} (26-week adherence)

The study was powered to detect a difference in selfreported non-adherence at 10 weeks' follow-up, as agreed with the funder. The study was not explicitly powered to detect a difference at 26 weeks but we collected the same outcome at 26 weeks, as a secondary outcome, to assess persistence of effect over time.

Adherence was assessed by telephone at 10 and 26 weeks using the same adherence measure used by pharmacists in the NMS, the 'NMS question', a question similar to the question in our original work ${ }^{3}$ : 'People often miss taking doses of their medicines, for a wide range of reasons. Have you missed any doses of your new medicine, or changed when you take it? (Prompt: when did you last miss a dose?). ${ }^{21}$

The patient was defined as non-adherent if any doses were missed without agreement with a medical professional in the previous 7 days. A sample size of 200 patients/arm was required to detect decreased 
non-adherence from $20 \%$ to $10 \%$ with $80 \%$ power, 5\% significance level (two tailed). Up to 100 patients were expected to be lost to follow-up, withdraw, or change/stop medication by 10 weeks, giving a required sample of 250 patients/arm.

\section{Other medicine-taking outcomes}

The Morisky Eight-Item Medication Adherence Scale (MMAS-8), validated in hypertension, was used with permission, to support our primary outcome measure, and collected via self-completion postal questionnaire at 10 and 26 weeks. ${ }^{22}$ Healthcare resource use was recorded via self-completed diaries provided to the patient, returned at 10 and 26 weeks. Whether a new medicine had been stopped or changed was recorded by the researcher conducting the telephone interview at 10 and 26 weeks.

\section{Data collection}

Research staff who interacted with patients were trained in minimising patient attrition. The NMStrained pharmacist in the pharmacy consented patients into the study. Patients were called by the research team up to seven times, inside and outside working hours. Prepaid envelopes were enclosed for return of data collection items. Return-to-sender stickers were attached to all outgoing mails. Where data were not returned before a scheduled telephone call, the researcher offered to collect these data over the phone. A final request to return any study questionnaires or diaries was made at week 26.

\section{Statistical analysis}

Complete case and intention-to-treat (ITT) analysis was applied in the same way for the 26 -week data as for the 10 -week analysis. ${ }^{73} 24$ Adherence rates were analysed using the $\chi^{2}$ test or Fisher's exact test. To assess the association between non-adherence and treatment group and also to account for important potential confounders (recruiting pharmacy, age, sex, disease, medication count) the following ITT analyses were completed:

- 'Naïve' results: (Model 1) simple logistic regression analysis to assess unadjusted effect of NMS on the outcome.

- Main analysis: (Model 2) logistic regression analysis, adjusting for factors that, ex ante, are expected to influence effect size.

- Missing data on outcome: (Model 3) multiple imputation by chained equations analysis of model 2 , to deal with missing data.

Models were derived for the primary outcome and for MMAS-8. Statistical analysis was conducted using Statistical Package for the Social Sciences (SPSS) V.20 25 and Stata V.13.0. ${ }^{26}$

Patients who reported adherence status (measured using the NMS question) at both 10 and 26 weeks were analysed separately for both treatment arms to explore changes in adherence using McNemar's test.

\section{NHS costs}

Resource use data up to 26-week follow-up were collected via patient diaries. These data were combined with NHS reference ${ }^{27}$ and Personal Social Services Research Unit ${ }^{28}$ unit costs to derive total costs (online supplementary appendix 3). The cost of providing the NMS intervention was added to this total. Comparisons between treatment arms at patient level were made using a two-sample t-test on the original data set, or on a bootstrapped data set, depending on the normality of the distribution of costs. ${ }^{29}$

\section{Economic analysis}

Trial design precluded observation of long-term outcomes and costs from changes in adherence. Many benefits of improved adherence are delivered well into the future. The cost-effectiveness of the NMS compared with normal practice was updated using 26-week adherence results. We simulated the effect of observed adherence increases on longer term patient outcomes (expressed as QALYs) and net NHS costs, following published reporting and model validation criteria. ${ }^{30}{ }^{31}$ We combined the results from the NMS trial with disease-specific models to generate estimates of patient outcomes and NHS costs, over a lifetime horizon, from an NHS perspective, weighted for the proportion of NMS episodes in each disease area (online supplementary appendix 4).

The detailed methods have been published as part of the economic analysis using 10-week effectiveness data. ${ }^{8}$ This updated analysis reports the impact of the 26-week effectiveness data on estimates of cost-effectiveness without changing any other parameters or model assumptions, using the UK Treasuryrecommended $3.5 \%$ discount rate for both costs and outcomes, using cost year 2014.

Six Markov models were developed in TreeAge Pro (TreeAge Software, Williamstown, MA, USA). The most commonly prescribed medicine within the NMS areas was used to inform a model representative of that disease group. For more details, see online supplementary appendix 5 . Each model described the consequences of being adherent to the medicine, compared with non-adherence. We were able to estimate, over a lifetime, how many QALYs would be generated, and level of NHS costs incurred, in a person who was adherent, or non-adherent, to their medicine. Summaries of probabilities, costs and utilities in the Markov models are provided in online supplementary appendix 5 .

Incremental costs and outcomes associated with each disease were incorporated additively into a composite probabilistic model and combined with adherence rates and intervention costs from the trial. Costs per QALY were calculated from the perspective of NHS England.

Deterministic and probabilistic incremental economic analyses were carried out. The incremental 
cost per QALY generated by NMS over normal practice was calculated using the following equation:

$\left(\operatorname{Cost}_{\mathrm{NMS}} \operatorname{Cost}_{\text {Normal practice }}\right) /\left(\mathrm{QALY} \mathrm{NMS}_{\mathrm{NMS}} \mathrm{QLY}_{\text {Normalpractice }}\right)$

Using Microsoft Excel, we used 5000 Monte Carlo simulations to obtain the incremental cost-effectiveness ratio (ICER) distribution. Negative ICERs are difficult to interpret and often arise when one of the interventions is either 'dominant' (more effective, less costly) or 'dominated' (less effective, more costly). It is not possible to tell this from the ICER itself. Costeffectiveness acceptability curves ${ }^{32}$ were constructed to express the probability that NMS is cost-effective as a function of the decision-maker's ceiling costeffectiveness ratio $(\lambda) .{ }^{33}$

\section{RESULTS}

Between July 2012 and September 2013, a total of 504 patients were recruited from 46 pharmacies (range
1-99 patients). (See online supplementary appendix 1 for CONSORT diagram.) The two groups had similar patient characteristics (table 1 ).

At 26 weeks, 41 and 25 patients had withdrawn from the normal practice and NMS arms, respectively. Reasons given for withdrawal were (normal practice, NMS arm): deceased $(1,0)$, not having time for study $(6,1)$, health reasons $(3,3)$, no longer interested in study $(3,3)$, no longer taking new medicine $(2,1)$, no specific reason stated $(13,11)$, patient had not started new medicine $(2,0)$, personal reasons or circumstances $(2,4)$, study design $(2,0)$, withdrawal due to recruitment issues $(3,1)$, patient had medicine before $(0,1)$ and withdrawal at randomisation $(4,0)$. At 26-week follow-up, 362/438 (83\%) phone calls were successful, 245/440 (56\%) of 26-week questionnaires were returned and 209/439 (48\%) of 6-month diaries were returned.

\begin{tabular}{|c|c|c|}
\hline Patient characteristics & $\begin{array}{l}\text { Normal practice } \\
\mathrm{n}(\%)\end{array}$ & $\begin{array}{l}\text { New Medicine Service } \\
\mathrm{n}(\%)\end{array}$ \\
\hline Total $n(\%)$ & $253(100.0)$ & $251(100.0)$ \\
\hline Antiplatelet/anticoagulant ( $n=43,8.5 \%)$ & $19(7.5)$ & $24(9.6)$ \\
\hline Asthma/COPD ( $n=117,23.2 \%)$ & $58(22.9)$ & $59(23.5)$ \\
\hline Hypertension $(n=249,49.4 \%)$ & $128(50.6)$ & $121(48.2)$ \\
\hline Type 2 diabetes $(n=95,18.8 \%)$ & $48(19.0)$ & $47(18.7)$ \\
\hline Female $(n=260,51.6 \%)$ & $135(53.4)$ & $125(49.8)$ \\
\hline Male $(n=244,48.4 \%)$ & $118(46.6)$ & $126(50.2)$ \\
\hline Total cohort age (years) (n: mean (SD)) & 253: $59.3(15.0)$ & 251: $59.5(15.3)$ \\
\hline Female age (years) (n: mean (SD)) & 135: $58.7(15.4)$ & $125: 56.8(16.0)$ \\
\hline Male age (years) (n: mean (SD)) & $118: 60.0(14.6)$ & $126: 62.2(14.1)$ \\
\hline Number of NMS eligible new medicine(s) at study entry, $n(\%)$ & Total NMS medicines: 257 & Total NMS medicines: 262 \\
\hline 1 & $249(98.4)$ & $241(96.0)$ \\
\hline 2 & $4(1.6)$ & $9(3.6)$ \\
\hline 3 & $0(0.0)$ & $1(0.4)$ \\
\hline Mean (SD) number of other medicines & $3.6(3.4)$ & $3.5(3.4)$ \\
\hline \multicolumn{3}{|l|}{ Economic deprivation based on IMD score* (mean (SD)) } \\
\hline Pharmacy study sites & $30.7(14.0)$ & $31.1(13.6)$ \\
\hline Study patients & $25.0(15.0)$ & $24.2(15.3)$ \\
\hline \multicolumn{3}{|l|}{ Location of pharmacy study site, $n(\%)$} \\
\hline Derbyshire (9 pharmacies) & $46(18.2)$ & $55(21.9)$ \\
\hline South Yorkshire (5 pharmacies) & $35(13.8)$ & $31(12.4)$ \\
\hline Leicestershire (8 pharmacies) & $15(5.9)$ & $10(4.0)$ \\
\hline Nottinghamshire (14 pharmacies) & $117(46.2)$ & $114(45.4)$ \\
\hline Greater London (10 pharmacies) & $40(15.8)$ & $41(16.3)$ \\
\hline \multicolumn{3}{|l|}{ Pharmacy ownershipt, $n(\%)$} \\
\hline Independent & $65(25.7)$ & $56(22.3)$ \\
\hline Large multiple & $63(24.9)$ & $68(29.1)$ \\
\hline Small multiple & $122(48.2)$ & $123(49.0)$ \\
\hline Supermarket & $3(1.2)$ & $4(1.6)$ \\
\hline
\end{tabular}

*Index of Multiple Deprivation (IMD) score: score is proportional to level of deprivation. A higher score indicates an area of higher deprivation (English deprivation scores range from 0.5 to 87.8 .

tLarge multiple and supermarket: the 10 largest pharmacy entities in England. Small multiple: pharmacies with six or more branches. Independent: pharmacies with one to five branches.

COPD, chronic obstructive pulmonary disease; NMS, New Medicine Service. 
Table 2 Reported adherence by patients to their new medicine (measured using the NMS question and Morisky Eight-Item Medication Adherence Scale (MMAS-8) and intention-to-treat analysis of the intervention as a predictor of adherence at weeks 10 and 26-frequency counts, unadjusted, adjusted and imputed ORs

\begin{tabular}{|c|c|c|c|c|}
\hline $\begin{array}{l}\text { Intention-to-treat analysis at } \\
\text { week } 10 \text { or } 26 \text { follow-up }\end{array}$ & $\begin{array}{l}\text { Adherent patients/total } \\
\text { responses, n (\%), P value }\end{array}$ & $\begin{array}{l}\text { Model 1* (naïve) } \\
\text { OR (95\% Cl, P value) }\end{array}$ & $\begin{array}{l}\text { Model } 2 \text { (main/adjusted) } \\
\text { OR ( } 95 \% \mathrm{Cl}, \mathrm{P} \text { value) }\end{array}$ & $\begin{array}{l}\text { Model } 3 \text { (imputation) } \\
\text { OR (95\% Cl, P value) }\end{array}$ \\
\hline \multicolumn{5}{|c|}{ 10-week follow-up: adherence as assessed by NMS question $(n=378)$} \\
\hline Normal practice & $115 / 190(60.5)$ & 1.00 & 1.00 & 1.00 \\
\hline NMS intervention & 133/188 (70.7), 0.037 & $1.58(1.03$ to $2.42,0.037)$ & $1.67(1.06$ to $2.62,0.027)$ & $\begin{array}{l}1.62(1.04 \text { to } 2.53 \\
0.032)\end{array}$ \\
\hline \multicolumn{5}{|c|}{ 26-week follow-up: adherence as assessed by NMS question $(n=327)$} \\
\hline Normal practice & $97 / 170(57.1)$ & 1.00 & 1.00 & 1.00 \\
\hline NMS intervention & 103/157 (65.6), 0.113 & $1.44(0.92$ to $2.25,0.114)$ & 1.50 (0.93 to $2.44,0.095)$ & $\begin{array}{l}1.50(0.89 \text { to } 2.51 \\
0.127)\end{array}$ \\
\hline \multicolumn{5}{|c|}{ Secondary outcomes (adherence as assessed by MMAS-8) } \\
\hline \multicolumn{5}{|c|}{ 10-week follow-up adherence MMAS-8 $(n=267)$} \\
\hline Normal practice & $85 / 143(59.4)$ & 1.00 & 1.00 & 1.00 \\
\hline NMS intervention & $89 / 124(71.8), 0.035$ & $1.74(1.04$ to $2.90,0.036)$ & $1.88(1.06$ to $3.34,0.030)$ & $\begin{array}{l}1.77(0.96 \text { to } 3.28, \\
0.068)\end{array}$ \\
\hline \multicolumn{5}{|c|}{ 26-week follow-up adherence MMAS-8 $(n=223)$} \\
\hline Normal practice & 70/124 (56.5) & 1.00 & 1.00 & 1.00 \\
\hline NMS intervention & $63 / 99(63.6), 0.277$ & $1.35(0.79$ to $2.32,0.278)$ & $1.60(0.84$ to $3.06,0.153)$ & $\begin{array}{l}1.43(0.70 \text { to } 2.91 \\
0.320)\end{array}$ \\
\hline
\end{tabular}

*Model 1 (naïve): simple logistic regression model. Model 2 (main/adjusted): logistic regression model adjusted for recruiting pharmacy, disease, age, sex and medication count. Model 3 (imputation): adjusted logistic regression model taking imputation of missing data into account.

NMS, New Medicine Service.

\section{Effect of NMS on adherence at 26 weeks}

Results for adherence, measured with the NMS question and MMAS- 8 at week 26 follow-up, are shown in table 2. For comparison, we show the data from week 10 which has previously been reported. ${ }^{7}$ All the analyses met statistical significance at week 10, but none achieved this at week 26 .

In the unadjusted complete case analysis of 327 patients still taking the initial medicine at 26 weeks, $97 / 170 \quad(57.1 \%)$ and 103/157 (65.6\%) $(\mathrm{p}=0.113)$ patients were adherent in the normal practice and NMS arms, respectively. In the main analysis (model 2), adherence yielded an OR of 1.50 (95\% CI 0.93 to $2.44, \mathrm{p}=0.095$ ), in favour of the NMS arm.

Marginal effects were estimated as probabilities for models 1 and 2 for primary and secondary outcomes at 26-week follow-up and are reported in the online supplementary appendix 6 . The method applied was marginal probabilities at the mean, given that all patients were in one or the other arm, respectively. These results suggest that, when using the NMS question to measure adherence, $69 \%$ of patients in the NMS arm were adherent to their medicine at 26 weeks, compared with $60 \%$ in the normal practice arm, an absolute difference of $9.0 \%$, but this difference is not statistically significant.

Three hundred and five patients responded by telephone at both 10 and 26 weeks, respectively, 191 patients returning questionnaires for both time points. Adherence for patients providing data at both time points shows little variation by arm or adherence measure in the overall cohort (table 3A). At the cohort level, reported changes in adherence behaviour (nonadherent patients becoming adherent or adherent patients becoming non-adherent) were similar in both arms (table 3B). In the NMS intervention arm, of 44 non-adherent patients, 17 (38.6\%) become adherent between 10 and 26 weeks. Of 102 adherent patients, 19 (18.6\%) become non-adherent, with no significant change in adherence between 10 and 26 weeks for the overall cohort (two-sided $\mathrm{p}=0.87$ ). In the normal

Table 3A Reported adherence by patients to their new medicine (measured using the NMS question and Morisky Eight-Item Medication Adherence Scale (MMAS-8)) for patients providing adherence data at both 10 and 26 weeks

\begin{tabular}{|c|c|c|c|c|}
\hline & \multicolumn{4}{|c|}{ Adherent patients/total responses, $\mathrm{n}(\%)$} \\
\hline & \multicolumn{2}{|c|}{ NMS question $(n=305)$} & \multicolumn{2}{|c|}{ MMAS-8 $(n=191)$} \\
\hline & 10 weeks & 26 weeks & 10 weeks & 26 weeks \\
\hline Normal practice & $94 / 159(59.1)$ & $94 / 159(59.1)$ & $63 / 112(56.3)$ & $62 / 112(55.4)$ \\
\hline NMS intervention & $102 / 146(69.9)$ & $100 / 146(68.5)$ & $57 / 79(72.2)$ & $55 / 79(69.6)$ \\
\hline
\end{tabular}

NMS, New Medicine Service 
Table 3B Reported adherence by patients to their new medicine (measured using the NMS question) showing response combinations for patients providing adherence data at both 10 and 26-week time points $(n=305)$

\begin{tabular}{|c|c|c|c|c|c|}
\hline & & \multicolumn{4}{|c|}{ 26-week response (n) } \\
\hline & & \multicolumn{2}{|l|}{ Normal practice } & \multicolumn{2}{|c|}{ NMS intervention } \\
\hline & & Non-adherent & Adherent & Non-adherent & Adherent \\
\hline \multirow[t]{2}{*}{ 10-week response $(\mathrm{n})$} & Non-adherent & 55 & 10 & 27 & 17 \\
\hline & Adherent & 10 & 84 & 19 & 83 \\
\hline \multicolumn{2}{|c|}{ OR (95\% Cl; two-sided p value)* } & \multicolumn{2}{|c|}{$1.00(0.37$ to $2.68 ; 1.0)$} & \multicolumn{2}{|c|}{$0.89(0.44$ to $1.82 ; 0.87)$} \\
\hline
\end{tabular}

*Repeated measures McNemar's test, OR $>1$ indicates improved adherence from 10 to 26 weeks, $O R=1$ no change, $0 R<1$ deteriorated adherence. NMS, New Medicine Service

practice arm, of 65 non-adherent patients, 10 (15.4\%) become adherent. Of 94 adherent patients, 10 (10.6\%) become non-adherent, with no significant change in adherence between 10 and 26 weeks for the overall cohort (two-sided $\mathrm{p}=1.0$ ).

By week 26, across both groups, there were 60 (13.7\%) reports of patients whose medicines had been changed and $52(11.9 \%)$ reports of patients with medicines stopped by their clinician. The medicine most frequently changed or stopped was amlodipine.

No reports of patient harm were reported to the study team by the patient, pharmacy team members, prescriber or researchers as a result of the intervention or participation in the study.

\section{Effect of NMS on NHS costs at 26-week follow-up} Mean (n, median, range, SD) total NHS costs for patients in normal practice and NMS arms are $£ 520.21(126, £ 244.97, £ 0-£ 4188.73, £ 62.04)$ and $£ 415.84(132, £ 212.02, £ 0-3384.06, £ 46.45)$, respectively. There was a general trend to reduced NHS costs, although statistically non-significant, for the NMS intervention: $-£ 104.36$ (95\% CI $£ 37.84$ to $-£ 256.52, \mathrm{p}=0.168)$.

\section{Economic analysis}

The probabilistic analysis reported that NMS generated a mean of 0.04 (95\% CI -0.01 to 0.13$)$ more QALYs per patient, at a mean reduced cost of $-£ 113.9$ (95\% CI -1159.4 to 683.7 ) (see table 4). The deterministic analysis reported very similar results (online supplementary appendix 4). The NMS dominates normal practice with probability of 0.653 (ICER: - $£ 2847.5$ per QALY, 2.5\%, 97.5\% percentiles: -38 $739.5,34024.2$ ) (see figure 1A). NMS has an $89.0 \%$ probability of cost-effectiveness compared with normal practice at a willingness to pay of $£ 20000$ per QALY (see figure 1B).

\section{DISCUSSION}

At week 26, the NMS increased the proportion of patients reporting adherence to their new medicine by $8.5 \%$ (65.6\%, compared with the $57.1 \%$ adherence in normal practice, $p=0.113)$. The adjusted effect size was $9.0 \%(p=0.095)$. This effect was of smaller magnitude than at week 10: $10.2 \%$, adjusted effect size $11.0 \% .^{7}$ This loss of statistical significance could be due to loss of effect of the intervention. A reduced sample size (51 fewer patients provided information), resulting in widened CIs, could also have had some influence.

At the study population level there was little difference between 10-week and 26-week findings. Patientlevel analysis suggests that there is mobility of patients between states of adherence, however this appears broadly even in both directions producing a net zero change, suggesting that at patient level, adherence is a dynamic behaviour over time, but, at population level, there is some degree of persistence of effect of NMS over time.

There is a bigger reduction in NHS costs at 26 weeks $(£ 104)$ than at 10 weeks $(£ 21),{ }^{7}$ but still not statistically significant. This could be due to a combination of loss of effect of NMS, patient attrition and high variability in patient costs. This bigger reduction could be attributed to the increased proportion of patients adhering to their medicines in the NMS arm having better disease control for 26 weeks leading to continued reduced use of (mostly secondary care) NHS resources. These results strengthen our earlier

\begin{tabular}{|c|c|c|c|c|c|c|}
\hline \multicolumn{2}{|c|}{ Mean cost $(2.5 \%, 97.5 \%$ percentiles $) / £$} & \multicolumn{2}{|c|}{ Mean QALY (2.5\%, 97.5\% percentiles) } & \multicolumn{2}{|c|}{$\begin{array}{l}\text { Incremental difference }(2.5 \%, 97.5 \% \\
\text { percentiles) }\end{array}$} & \multirow{2}{*}{$\begin{array}{l}\text { ICER: f/QALY } \\
(2.5 \%, 97.5 \% \\
\text { percentiles) }\end{array}$} \\
\hline NMS* & Normal practice & NMS & Normal practice & Cost/f & QALY & \\
\hline $\begin{array}{l}20482.7(9438.9,53 \\
822.0)\end{array}$ & $\begin{array}{l}20596.5(9435.5,54 \\
125.5)\end{array}$ & $13.45(12.55,14.35)$ & $13.41(12.50,14.31)$ & $\begin{array}{l}-113.9(-1159.4 \\
683.7)\end{array}$ & $0.04(-0.01,0.13)$ & $\begin{array}{l}-2847.5(-38739.5, \\
34024.2)\end{array}$ \\
\hline
\end{tabular}

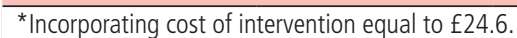

ICER, incremental cost-effectiveness ratio; NMS, New Medicine Service; QALY, quality-adjusted life-year. 
A

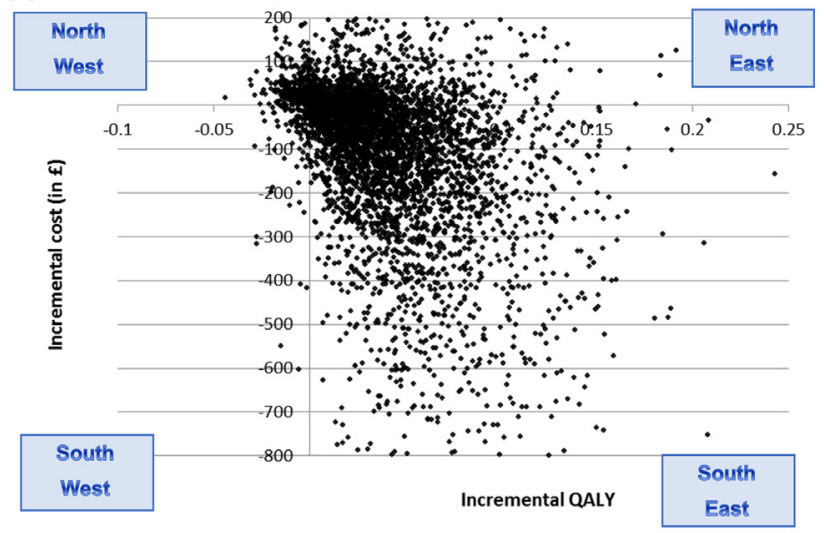

B

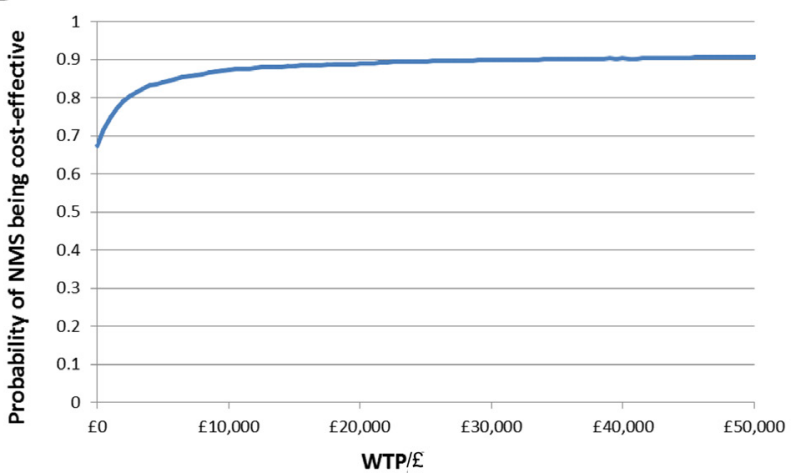

Figure 1 (A) Incremental cost-effectiveness plane: NMS intervention versus current practice. (B) Cost-effectiveness acceptability curve (NMS intervention vs current practice). This graph demonstrates the probability of cost-effectiveness at a range of decision-maker ceiling willingness-to-pay values for the NMS intervention overall. NMS, New Medicine Service; QALY, quality-adjusted life-year; WTP, willingness to pay.

conclusions that the short-term cost of NMS to the NHS is absorbed by reduced NHS costs.

The economic evaluation suggests NMS will deliver better patient outcomes, measured as QALYs, than normal practice at overall reduced costs to the NHS in the long term. At 26 weeks, NMS has an $89.0 \%$ probability of cost-effectiveness compared with normal practice at a willingness to pay of $£ 20000$ per QALY, which is the threshold for costeffectiveness in the NHS in England. This is despite the loss of statistical significance of the effect size at 26 weeks contributing to increased uncertainty around ICER point estimates.

\section{Strengths and limitations}

Key strengths of this study are the rigorous design, pragmatic nature, economic analysis, long-term follow-up, and extensive observational and interviewbased work alongside the RCT to examine implementation from the perspectives of patients, pharmacy teams and prescribers. ${ }^{34-36}$

The study was powered for the evaluation of effectiveness at 10 weeks, with 26 weeks being designed, a priori, as a secondary outcome. This priority was agreed with the Department of Health, which funded the study. We were also aware that so little was known about the possible future outcomes at 26 weeks that there would have been significant uncertainty in any sample size estimation. Unfortunately, there was insufficient funding to conduct the 26-week analysis and the research team dispersed, leading to the delay between this paper and the presentation of the 10-week adherence data in 2016 and economic analysis in 2017.

Sixty-six patients withdrew between weeks 10 and 26, 62\% from the normal practice arm; the CIs increased, the effect size diminished and did not meet statistical significance at the $p=0.05$ level. Patient attrition at 26 weeks is not surprising given the commitment and motivation needed to take part over a long period of time. Patients may feel more confident using the medicine and therefore motivation to continue with the study may have reduced. They may also forget about the study, especially those in the control arm.

A further limitation was the use of a patient-reported behavioural process measure, and the need to extrapolate from this to estimate impact on patient health and healthcare provider costs. There is no gold standard for measuring patients' medicine adherence. We used two self-report measures to provide an internal check on validity. ${ }^{37}$ Although self-report tends to return a higher rate of medication adherence $(+15 \%)$ than some objective measures, it correlates with objective clinical measures. ${ }^{38}$ We minimised biases through confidential interview, ${ }^{39}$ made efforts to normalise non-adherence by recognising the challenges of taking regular medications and asked about missed doses only in the week prior to data collection, to optimise recall. ${ }^{40}$ Some confidence is given by our use of both telephone and postal methods for reporting adherence, which yielded similar ORs.

Adherence to medicines for long-term conditions drops over time, ${ }^{41-43}$ so adherence was expected to drop in the normal care arm. We assumed it would drop by a similar extent in the NMS group. ${ }^{8}$ The results from the 26-week analysis partially support this, as the effect size reduced from $11.0 \%$ at 10 weeks to $9.0 \%$ at 26 weeks. The apparent partially sustained effect is encouraging, given effects of cognitive interventions tend to reduce over time, particularly short 'one-off' interventions. This may suggest that if problems are caught early there is some partial maintenance of effect, but additional work is required to examine this further.

A limitation of the economic evaluation is the paucity of published evidence upon which to base the estimates of economic impact of adherence in the individual disease-drug pairs, particularly the variety of ways in which adherence is measured in different studies, and the link between adherence and outcome. The wide range around the point estimates of costeffectiveness reflects the lack of statistically significant 
difference in adherence, and the uncertainty in some of the individual adherence models.

\section{Implications for clinicians and policymakers}

Since approval, the NMS has had wide and sustained adoption in England. To the end of December 2018, 5.718 million consultations have been claimed for in England, with over 926000 in the year 2017/2018, and 12036 pharmacies have claimed for at least one NMS consultation. ${ }^{44}$ Estimates of the benefits of NMS since its introduction, using the current economic evaluation, are $£ 651.8$ million long-term cost savings to the NHS and 228715 QALYs gained.

To understand perception, implementation and execution of NMS in a real-world setting, our work included in-depth exploration of NMS with key stakeholders (patients, prescribers, pharmacists), providing essential insight into future developments and commissioning. ${ }^{34-36}$ The NMS workload had been absorbed into pharmacists' daily routines alongside existing responsibilities with no extra resources or evidence of reduction in other responsibilities. ${ }^{34}$ We found pharmacists were pragmatic, simplifying and adapting the NMS to facilitate its delivery which may have affected fidelity and thus effectiveness. Pharmacist understanding of the NMS was found to impact on what they believed should be achieved from the service. ${ }^{36}$ Patients who had few problems with medicines had varied reactions to the service. ${ }^{36}$ Where there was ambiguity or poor prior understanding of the NMS, people were reluctant to engage with the service. As the service becomes more embedded in practice, and as patients become more accustomed to such interactions, it is likely that patients will be able to frame the service as intended and so potentially benefit from the support offered. A review of promotional and public campaigns is needed to generate engagement among publics who may be indifferent, medically underserved or unacquainted with newer pharmacy services. ${ }^{34} 3645$ The NMS results in a more complex configuration of relational power between pharmacists, patients and prescribers. ${ }^{35}$ We found that GPs were generally supportive of the initiative but unaware of the service or potential benefits. The service is likely to gain greater traction if it was seen to align with prescribers' priorities. ${ }^{36}$

The NMS was designed to be the first step in supporting a patient starting to use medicines to maintain a long-term condition. A very similar intervention has been demonstrated to have similar effectiveness in people established on statins or diabetic medicines. ${ }^{46}$ This suggests that using this approach when the medicine is started, and reviewing it every 6 months (NHS England already funds pharmacists to conduct six monthly reviews of patients on several long-term medications), could have a sustained effect. Such a service would support national policy. NHS England proposes more appropriate clinical use of community pharmacy, ${ }^{47}$ and has introduced clinical pharmacists into primary care doctor's practices. ${ }^{48}$ It is essential to examine how NMS integrates with these primary care service developments.

\section{CONCLUSIONS}

At 26-week follow-up, NMS no longer demonstrated a statistically significant increase in adherence or reduction in NHS costs, which may be attributable to patient attrition from the study. Long-term economic evaluation suggested NMS may deliver better patient outcomes and reduced overall healthcare costs than normal practice at 26 weeks, with findings of increased health gain with NMS over normal practice at a cost per QALY well below most accepted thresholds for technology implementation. ${ }^{49}$ However, uncertainty around this finding is very high, and more work is needed to understand how to sustain intervention effects over time.

Author affiliations

${ }^{1}$ Manchester Centre for Health Economics, School of Health Sciences, University of Manchester, Manchester, UK

${ }^{2}$ Division of Pharmacy Practice and Policy, University of Nottingham School of Pharmacy, Nottingham, UK

${ }^{3}$ Department of Economics, Kozminski University, Warsaw, Poland

${ }^{4}$ School of Pharmacy, UCL School of Pharmacy, London, UK

${ }^{5}$ Primary Care, University of Nottingham, Nottingham, UK

${ }^{6}$ School of Medicine and Dentistry, University of Birmingham, Birmingham, UK

${ }^{7}$ School of Pharmacy, Health Bridge, London, UK

${ }^{8}$ School of Medicine, University of Nottingham, Nottingham, UK

${ }^{9}$ Institute of Mental Health, CLAHRC East Midlands, Nottingham, UK

${ }^{10}$ School of Health Sciences, University of Nottingham, Nottingham, UK

${ }^{11}$ Nottingham University Business School, University of Nottingham,

Nottingham, UK

${ }^{12}$ School of Pharmacy, 68 Brighton Cottages, Haywards Heath, UK

Acknowledgements The team are grateful to Professor Donald E Morisky, Department of Community Health Sciences, UCLA School of Public Health, for granting copyright permission to use the MMAS-8 adherence tool for this research. Use of the CMMAS is protected by US copyright laws. Permission for use is required. A licence agreement is available from: Donald E Morisky, ScD, ScM, MSPH, Professor, Department of Community Health Sciences, UCLA School of Public Health, 650 Charles E Young Drive South, Los Angeles, CA 90095 -

1772.

Funding This study was funded by the Department of Health Policy Research Programme.

Disclaimer The views expressed in this article are those of the author(s) and not necessarily those of the NHS, the NIHR or the Department of Health.

Competing interests None declared.

Patient consent for publication Not required.

Ethics approval The National Research Ethics Service (NRES) West Midlands-Black Country Research Ethics Committee (12/ WM/0096), 2 May 2012.

Provenance and peer review Not commissioned; externally peer reviewed.

Data availability statement Data are available upon reasonable request.

Open access This is an open access article distributed in accordance with the Creative Commons Attribution 4.0

Unported (CC BY 4.0) license, which permits others to copy, redistribute, remix, transform and build upon this work for any 
purpose, provided the original work is properly cited, a link to the licence is given, and indication of whether changes were made. See: https://creativecommons.org/licenses/by/4.0/.

\section{ORCID iDs}

Rachel Ann Elliott http://orcid.org/0000-0002-3650-0168 Matthew J Boyd http://orcid.org/0000-0003-2997-5090

\section{REFERENCES}

1 Department of Health. Pharmacy in England: Building on strengths - delivering the future, 2008. Available: http://www. dh.gov.uk/en/Publicationsandstatistics/Publications/Publications PolicyAndGuidance/DH_083815

2 Leventhal H, Cameron L. Behavioral theories and the problem of compliance. Patient Educ Couns 1987;10:117-38.

3 Clifford S, Barber N, Elliott R, et al. Patient-Centred advice is effective in improving adherence to medicines. Pharm World Sci 2006;28:165-70.

4 Elliott RA, Clifford S, Barber N, et al. The cost effectiveness of a pharmacy Advisory service to improve adherence to medicines. Pharmacy World and Science 2008;30:17-23.

5 Barber N, Parsons J, Clifford S, et al. Patients' problems with new medication for chronic conditions. Qual Saf Health Care 2004;13:172-5.

6 Pharmaceutical Services Negotiating Committee. New medicines service, 2011. Available: http://www.psnc.org.uk/ pages/nms.html [Accessed 12 Aug 2011].

7 Elliott RA, Boyd MJ, Salema N-E, et al. Supporting adherence for people starting a new medication for a long-term condition through community pharmacies: a pragmatic randomised controlled trial of the new medicine service. BMJ Qual Saf 2016;25:747-58.

8 Elliott RA, Tanajewski L, Gkountouras G, et al. Cost effectiveness of support for people starting a new medication for a long-term condition through community pharmacies: an economic evaluation of the new medicine service (NmS) compared with normal practice. Pharmacoeconomics 2017;35:1237-55.

9 Pharmacy Services Negotiating Committee. Summary of 2014/15 community pharmacy contractual framework agreement, 2014. Available: https://psnc.org.uk/wp-content/ uploads/2014/09/Summary-of-CPCF-changes-for-2014-15-pdf. pdf [Accessed 01 Oct 2016].

10 National Health Service. Pharmacy services: new medicine service (NmS), 2017. Available: https://www.nhs.uk/video/ Pages/new-medicines-service.aspx [Accessed 12 Oct 2018].

11 Finance eHealth \& Pharmaceuticals Directorate Pharmacy \& Medicines Division NHS Scotland. Additional pharmaceutical services: chronic medication service: high risk and new medicine intervention support tools for the pharmacy care record, NHS circular: PCA (P) (2012) 19, 2012. Available: https://www.sehd.scot.nhs.uk/pca/PCA2012\%28P\%2919.pdf [Accessed 18 Nov 2018].

12 NPS MedicineWise. New medicines support service study, 2017. Available: https://www.nps.org.au/nmss [Accessed 18 Nov 2018].

13 Apotekforeningen. Medisinstart blir vedtatt AV Stortinget, 2017. Available: https://www.apotek.no/nyhetsarkiv/ helsepolitikk/medisinstart-blir-vedtatt-av-stortinget [Accessed 18 Nov 2018].

14 Irish Pharmacy Union. Irish pharmacy Union new medicines service pilot report, 2017. Available: https://ipu.ie/wp-content/ uploads/2017/12/IPU-NMS-Pilot-2017-Report-Copy.pdf [Accessed 18 Nov 2018].
15 Koninklijk Limburgs Apothekers Verbond.

Begeleidingsgesprekken nieuwe medicatie, 2017. Available: https://www.klav.be/klavinfo/nl/dossiers/begeleidingsgesp rekken-nieuwe-medicatie [Accessed 18 Nov 2018].

16 Fraeyman J, Foulon V, Mehuys E, et al. Evaluating the implementation fidelity of new medicines service for asthma patients in community pharmacies in Belgium. Res Social Adm Pharm 2017;13:98-108.

17 Boyd M, Waring J, Barber N, et al. Protocol for the new medicine service study: a randomized controlled trial and economic evaluation with qualitative appraisal comparing the effectiveness and cost effectiveness of the new medicine service in community pharmacies in England. Trials 2013;14:411.

18 Elliott RA, Boyd M, Waring J, et al. Understanding and Appraising the New Medicines Service in the NHS in England (029/0124)' A randomised controlled trial and economic evaluation with qualitative appraisal comparing the effectiveness and cost effectiveness of the New Medicine Service in community pharmacies in England University of Nottingham, 2014. Available: http://www.nottingham.ac.uk/ pazmjb/nms/downloads/report/files/assets/common/downloads/ 108842\%20A4\%20Main\%20Report.v4.pdf [Accessed 10 Oct 2015].

19 Schulz KF, Altman DG, Moher D, et al. Consort 2010 statement: updated guidelines for reporting parallel group randomised trials. BMJ 2010;340.

20 SAS Institute Inc. SAS Version 9.3(TS1M1). SAS Institute Inc. NC, USA: Cray, 2011.

21 Pharmaceutical Services Negotiating Committee, NHS Employers. NHS Community Pharmacy Contractual Framework 2011/12 Service Developments - Latest Information, 2011. Available: http://www.psnc.org.uk/data/ files/PharmacyContract/Contract_changes_2011/summary_of_ cpcf_changes_may_2011.pdf [Accessed 4 Aug 2011].

22 Morisky DE, Ang A, Krousel-Wood M, et al. Predictive validity of a medication adherence measure in an outpatient setting. $J$ Clin Hypertension 2008;10:348-54.

23 Hollis S, Campbell F. What is meant by intention to treat analysis? survey of published randomised controlled trials. BMJ 1999;319:670-4.

24 Shih WJ. Problems in dealing with missing data and informative censoring in clinical trials. Curr Control Trials Cardiovasc Med 2002;3:4.

25 IBM Corp. Ibm SPSS statistics for windows, version 20.0. Armonk: NY, 2011.

26 StataCorp LP. Stata data analysis and statistical Software. Special Edition Release 101 edition, 2008.

27 National Health Service Executive. Nhs reference costs 2012-13, 2013. Available: https://www.gov.uk/government/ publications/nhs-reference-costs-2012-to-2013 [Accessed 10 Oct 2014].

28 Personal Social Services Research Unit (PSSRU). Unit costs of health and social care. In Curtis L, ed, 2012.

29 Briggs A, Gray A. The distribution of health care costs and their statistical analysis for economic evaluation. J Health Serv Res Policy 1998;3:233-45.

30 Husereau D, Drummond M, Petrou S, et al. Consolidated health economic evaluation reporting standards (cheers) statement. Pharmacoeconomics 2013;31:361-7.

31 Vemer P, Corro Ramos I, van Voorn GAK, et al. AdViSHE: a Validation-Assessment tool of Health-Economic models for decision makers and model users. Pharmacoeconomics 2016;34:349-61. 
32 Fenwick E, Byford S. A guide to cost-effectiveness acceptability curves. British Journal of Psychiatry 2005;187:106-8.

33 Fenwick E, Claxton K, Sculpher M. Representing uncertainty: the role of cost-effectiveness acceptability curves. Health Econ 2001;10:779-87.

34 Latif A, Waring J, Watmough D, et al. Examination of England's new medicine service (NmS) of complex health care interventions in community pharmacy. Res Social Adm Pharm 2016;12:966-89.

35 Waring J, Latif A, Boyd M, et al. Pastoral power in the community pharmacy: a Foucauldian analysis of services to promote patient adherence to new medicine use. Soc Sci Med 2016;148:123-30.

36 Latif A, Waring J, Watmough D, et al. 'I expected just to walk in, get my tablets and then walk out': on framing new community pharmacy services in the English healthcare system. Sociol Health Illn 2018;40:1019-36.

37 Horne R, Barber N, Weinman J, et al. Concordance, adherence and compliance in medicine taking: a scoping exercise. London: NIHR Service Delivery and Organisation, 2006.

38 Murri R, Ammassari A, Gallicano K, et al. Patient-Reported nonadherence to HAART is related to protease inhibitor levels. J Acquir Immune Defic Syndr 2000;24:123-8.

39 Butler JA, Peveler RC, Roderick P, et al. Measuring compliance with drug regimens after renal transplantation: comparison of self-report and clinician rating with electronic monitoring. Transplantation 2004;77:786-9.

40 Lehmann A, Aslani P, Ahmed R, et al. Assessing medication adherence: options to consider. Int J Clin Pharm 2014;36:55-69.
41 Caro JJ, Salas M, Speckman JL, et al. Persistence with treatment for hypertension in actual practice. Canadian Medical Association Journal 1999;160:31-7.

42 Vrijens B, Vincze G, Kristanto P, et al. Adherence to prescribed antihypertensive drug treatments: longitudinal study of electronically compiled dosing histories. BMJ 2008;336:1114-7.

43 Morgan SG, Yan L. Persistence with hypertension treatment among community-dwelling be seniors. Can J Clin Pharmacol 2004;11:e267-73.

44 Pharmaceutical Services Negotiating Committee. Nms statistics 2017/18: London, 2018. Available: http://psnc.org.uk/fundingand-statistics/nhs-statistics/nms-statistics/ [Accessed $18 \mathrm{Nov}$ 2018].

45 Nisbet MC, Scheufele DA. What's next for science communication? promising directions and lingering distractions. Am J Bot 2009;96:1767-78.

46 Lyons I, Barber N, Raynor DK, et al. The medicines advice service evaluation (MASE): a randomised controlled trial of a pharmacist-led telephone based intervention designed to improve medication adherence. BMJ Qual Saf 2016;25:759-69.

47 National Health Service. The five year forward view, the NHS plan for the future, 2014. Available: https://www.england.nhs. uk/wp-content/uploads/2014/10/5yfv-web.pdf [Accessed 18 Nov 2018].

48 Mann C, Anderson CA, AJ A, et al. Clinical pharmacists in general practice: pilot scheme. Independent Evaluation Report: Full Report: University of Nottingham, 2018.

49 McCabe C, Claxton K, Culyer AJ. The NICE cost-effectiveness threshold: what it is and what that means. Pharmacoeconomics 2008;26:733-44. 